\title{
Effects on Heat Transfer Coefficient and Adiabatic Effectiveness in Combined Backside and Film Cooling with Short-Hole Geometry
}

\author{
Renzo La Rosa
}

Thesis submitted to the faculty of the Virginia Polytechnic Institute and State University in partial fulfillment of the requirements for the degree of

Master of Science

In

Mechanical Engineering

Wing F. Ng, Chair

James R. Mahan

Clinton L. Dancey

June 28, 2018

Blacksburg, VA

Keywords: Heat Transfer, Double Wall, HTC, Film Cooling, Effectiveness, Gas Turbines 


\title{
Effects on Heat Transfer Coefficient and Adiabatic Effectiveness in Combined Backside and Film Cooling with Short-Hole Geometry
}

\begin{abstract}
Heat transfer experiments were done on a flat plate to study the effect of internal counter-flow backside cooling on adiabatic film cooling effectiveness and heat transfer coefficient. In addition, the effects of density ratio (DR), blowing ratio (BR), diagonal length over diameter (L/D) ratio, and Reynolds number were studied using this new configuration. The results are compared to a conventional plenum fed case. Data were collected up to $X / D=23$ where $X=0$ at the holes, an $S / D$ $=1.65$ and $\mathrm{L} / \mathrm{D}=1,2$. Testing was done at low $\mathrm{L} / \mathrm{D}$ ratios since short holes are normally found in double wall cooling applications in turbine components. A DR of 2 was used in order to simulate engine-like conditions and this was compared to a DR of 0.92 since relevant research is done at similar low DR. The BR range of 0.5 to 1.5 was chosen to simulate turbine conditions as well. In addition, previous research shows that peak effectiveness is found within this range. Infrared (IR) thermography was used to capture temperature contours on the surface of interest and the images were calibrated using a thermocouple and data analyzed through MATLAB software. A heated secondary fluid was used as 'coolant' in the present study. A steady state heat transfer model was used to perform the data reduction procedure. Results show that backside cooling configuration has a higher adiabatic film cooling effectiveness when compared to plenum fed configurations at the same conditions. In addition, the trend for effectiveness with varying BR is reversed when compared with traditional plenum fed cases. Yarn flow visualization tests show that flow exiting the holes in the backside cooling configuration is significantly different when compared to flow exiting the plenum fed holes. We hypothesize that backside cooling configuration has flow exiting the holes in various directions, including laterally, and behaving similar to slot film cooling, explaining the differences in trends. Increasing DR at constant BR shows an increase in adiabatic effectiveness and HTC in both backside cooling and plenum fed configurations due to the decreased momentum of the coolant, making film attachment to the surface more probable. The effects of $\mathrm{L} / \mathrm{D}$ ratio in this study were negligible since both ratios used were small. This shows that the coolant flow is still underdeveloped at both $\mathrm{L} / \mathrm{D}$ ratios. The study also showed that increasing turbulence through increasing Reynolds number decreased adiabatic effectiveness.
\end{abstract}




\section{Effects on Heat Transfer Coefficient and Adiabatic Effectiveness in Combined Backside and Film Cooling with Short-Hole Geometry}

\section{General Audience Abstract}

Gas turbine engines are used for multiple applications for power (power plants) or thrust (aircraft propulsion). Engine efficiency is correlated with higher working temperatures, which exceed the melting points of the materials being used. Therefore, more efficient cooling techniques are needed in order to protect the engine turbine components, such as blades and vanes. Relatively cooler air is bypassed from the compressor to the turbine section to cool the turbine components from the high temperatures. The air flows through the turbine components and out through machined holes referred to as film cooling holes. A protective layer, or film, protects the external region of the blade or vane. Previous research has found that the geometry of the airfoils used and the flow conditions play a major role in heat transfer. Most of the relevant research use a model that contains one-sided heat transfer. The present study focuses on combined backside and film cooling heat transfer, with different geometries and flow conditions, using a steady-state model for the data reduction procedure. 


\section{Table of Contents}

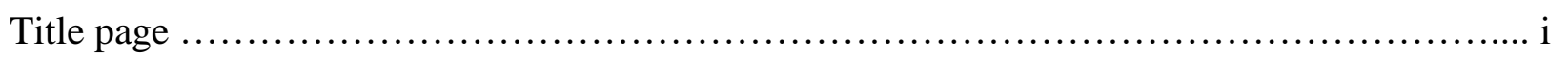

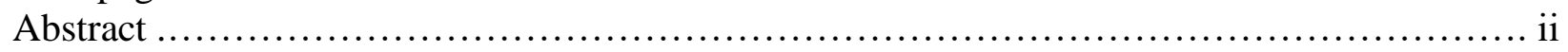

General Audience Abstract ........................................................... iii

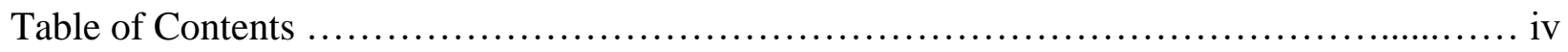

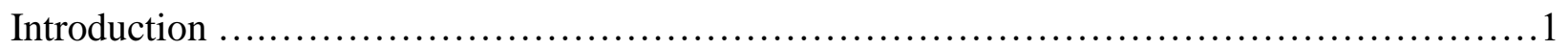

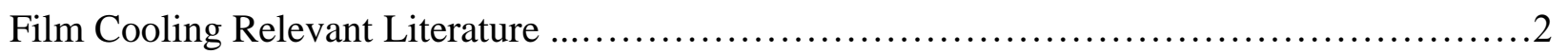

Experimental Method ............................................................... 3

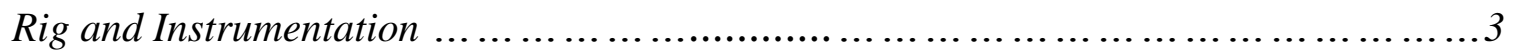

Test Section ..............................................................4

Data Reduction Method ....................................................

Test Conditions ........................................................... 6

Experimental Results .............................................................6

Effects of Backside Cooling .................................................6

Effects of Density Ratio .................................................... 7

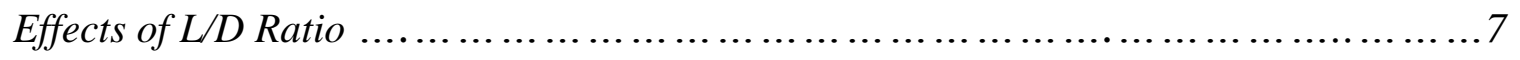

Effects of Reynolds Number............................................. 8

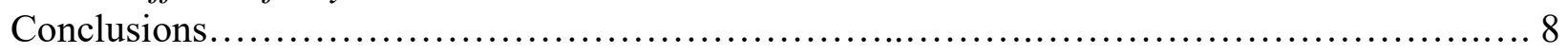

Nomenclature.................................................................. 9

Acknowledgements................................................................ 9

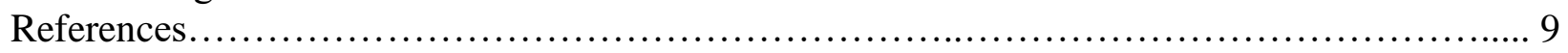

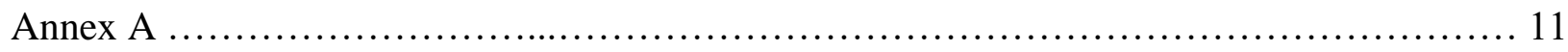

List of Figures .............................................................

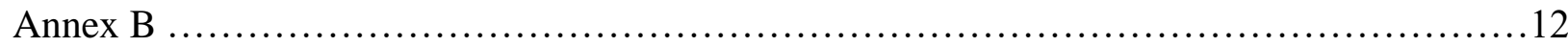

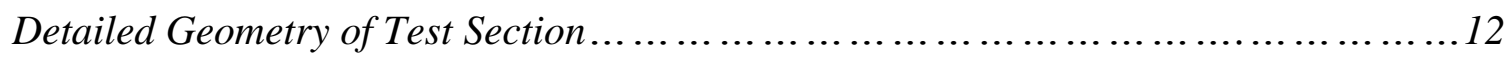

Details on Instrumentation .............................................. 13

Annex C......................................................................... 15

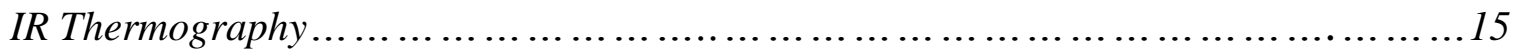

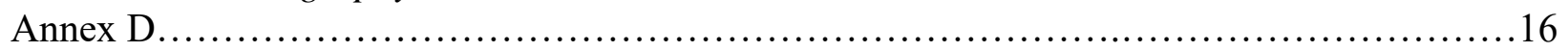

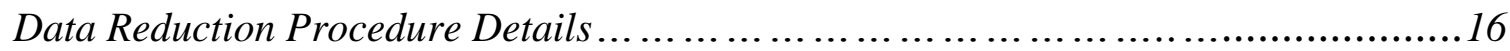

Annex E............................................................................ 17

Details on BSC Result Hypothesis ............................................. 17 


\section{Put paper number here}

\section{EFFECTS ON HEAT TRANSFER COEFFICIENT AND ADIABATIC EFFECTIVENESS IN COMBINED BACKSIDE AND FILM COOLING WITH SHORT-HOLE GEOMETRY}

\author{
Renzo La Rosa \\ Virginia Polytechnic Institute and State University \\ Blacksburg, VA, U.S.A.
}

\author{
Dr. Jaideep Pandit \\ Virginia Polytechnic Institute and State University \\ Blacksburg, VA, U.S.A.
}

\author{
Dr. Wing $\mathbf{~ g g}$ \\ Virginia Polytechnic Institute and \\ State University \\ Blacksburg, VA, U.S.A.
}

\author{
Brett Barker \\ Rolls Royce Corporation \\ Indianapolis, IN, U.S.A.
}

\begin{abstract}
Heat transfer experiments were done on a flat plate to study the effect of internal counter-flow backside cooling on adiabatic film cooling effectiveness and heat transfer coefficient. In addition, the effects of density ratio (DR), blowing ratio (BR), diagonal length over diameter (L/D) ratio, and Reynolds number were studied using this new configuration. The results are compared to a conventional plenum fed case. Data were collected up to $\mathrm{X} / \mathrm{D}=23$ where $\mathrm{X}=0$ at the holes, an $\mathrm{S} / \mathrm{D}=1.65$ and $\mathrm{L} / \mathrm{D}=1,2$. Testing was done at low $\mathrm{L} / \mathrm{D}$ ratios since short holes are normally found in double wall cooling applications in turbine components. A DR of 2 was used in order to simulate engine-like conditions and this was compared to a DR of 0.92 since relevant research is done at similar low DR. The BR range of 0.5 to 1.5 was chosen to simulate turbine conditions as well. In addition, previous research shows that peak effectiveness is found within this range. Infrared (IR) thermography was used to capture temperature contours on the surface of interest and the images were calibrated using a thermocouple and data analyzed through MATLAB software. A heated secondary fluid was used as 'coolant' in the present study. A steady state heat transfer model was used to perform the data reduction procedure. Results show that backside cooling configuration has a higher adiabatic film cooling effectiveness when compared to plenum fed configurations at the same conditions. In addition, the trend for effectiveness with varying BR is reversed when compared with traditional plenum fed cases. Yarn flow visualization tests show that flow exiting the holes in the backside cooling configuration is significantly different when compared to flow exiting the plenum fed holes. We hypothesize that backside cooling configuration has flow exiting the holes in various directions, including laterally, and behaving similar to slot film cooling,
\end{abstract}

explaining the differences in trends. Increasing DR at constant BR shows an increase in adiabatic effectiveness and HTC in both backside cooling and plenum fed configurations due to the decreased momentum of the coolant, making film attachment to the surface more probable. The effects of L/D ratio in this study were negligible since both ratios used were small. This shows that the coolant flow is still underdeveloped at both L/D ratios. The study also showed that increasing turbulence through increasing Reynolds number decreased adiabatic effectiveness.

\section{INTRODUCTION}

Gas turbine engines are used in various industries ranging from aerospace to industrial to maritime applications. Higher operating temperatures are desired in order to keep up with demand for higher thermodynamic engine efficiency. The materials used in the engine's hot section, the combustor and high pressure turbine, however, are limiting factors in the maximum temperature that can be achieved. At the turbine, since the turbine inlet temperature (TIT) is the driver for engine efficiency, research continues to focus on increasing this value. Yin et al. [1] report the increase in TIT over the past few decades, with most engines having a TIT $>1500^{\circ} \mathrm{C}$. For this reason, research has been focused on finding or creating better materials and introducing more efficient cooling techniques.

Since the 1960s, cooling techniques have been implemented in order to accommodate the increasing engine operating temperatures. Bleed air from the compressor bypasses the combustor and travels through the internal parts of the turbine blades and vanes. This type of cooling is known as convection cooling. In the 1970s, the concept of film cooling was introduced to provide external cooling to the surface. Goldstein et al. [2] defined film cooling as "the introduction of a secondary fluid at 
one or more discrete locations along a surface exposed to a high temperature environment to protect that surface not only in the immediate region of injection, but also in the downstream region." As the secondary fluid is introduced, a film boundary layer develops. This is illustrated in Figure 1, which shows flow over a flat plate with film cooling.

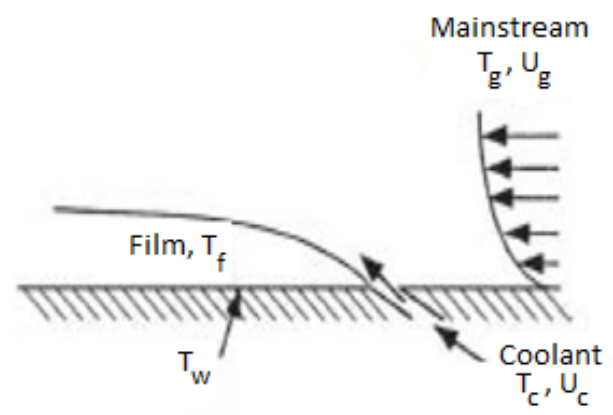

Figure 1: Film cooling over a flat plate. Secondary (coolant) fluid introduced to cool external surface.

The performance of a film cooling design is measured by the adiabatic film cooling effectiveness, commonly represented by the Greek letter $\boldsymbol{\eta}$ (eta), where:

$$
\eta \equiv \frac{T_{g}-T_{f}}{T_{g}-T_{C}}
$$

It is observed that the driver for heat transfer to/from the wall is the film temperature, otherwise known as the adiabatic wall temperature, $T_{f}$. Since the introduction of film cooling, there has been extensive research to optimize the cooling technique.

\section{FILM COOLING RELEVANT LITERATURE}

Goldstein et al. [2], Bogard and Thole [3], Saumweber et al. [4], and others have shown that effectiveness is sensitive to hole geometry. In their review of film cooling, Bogard and Thole [3] showed that the optimal injection angle is between 25-35 deg to the wall for both coolant attachment and manufacturing feasibility. Goldstein et al. [2] review various studies that were done in the 1970s regarding hole shape. Saumweber et al. [4] compares the results of some of the more modern film cooling shaped hole designs that are in use today. Bunker [5] shows that only shaped holes at the exit play a major role. Shaped holes increase the exit area, which in turn reduces the coolant's momentum, thus increasing the probability that the coolant will attach to the surface and form the protective film.

Haven et al. [6,7] show how cylindrical holes create kidney vortices, which aids in the detachment of the coolant from the surface. Shaped holes create anti kidney vortices, counter-acting this effect. Ramesh et al. [8] show a similar effect using tripod holes.

In addition to hole geometry, Bogard and Thole [3] and Ekkad and Han [9] among others show that adiabatic effectiveness and heat transfer coefficient are also functions of the flow conditions. Ekkad and Han [9] review the effect of density ratio (DR) and blowing ratio (BR) on effectiveness. The definitions for both of these parameters are shown in Equations 2 and 3 and will be used in the present study:

$$
\begin{gathered}
D R=\frac{\rho_{\text {coolant }}}{\rho_{\text {mainstream }}} \\
B R=\frac{(\rho U)_{\text {coolant }}}{(\rho U)_{\text {mainstream }}}=D R * \frac{U_{\text {coolant }}}{U_{\text {mainstream }}}
\end{gathered}
$$

Ekkad and Han [9] show that at a fixed BR, effectiveness increases with increasing DR. Equation 3 shows that the coolant momentum is reduced in this case due to the inverse relationship between $\mathrm{DR}$ and velocity ratio (VR). In addition, their review also show that peak effectiveness is found generally in the BR range of 0.4-1 for DR up to 2, as shown in Figure 2. Increasing $\mathrm{BR}$ past this range decreases effectiveness due to the high momentum of the coolant as it exits the hole, causing secondary fluid to lift off and not attach to the surface.

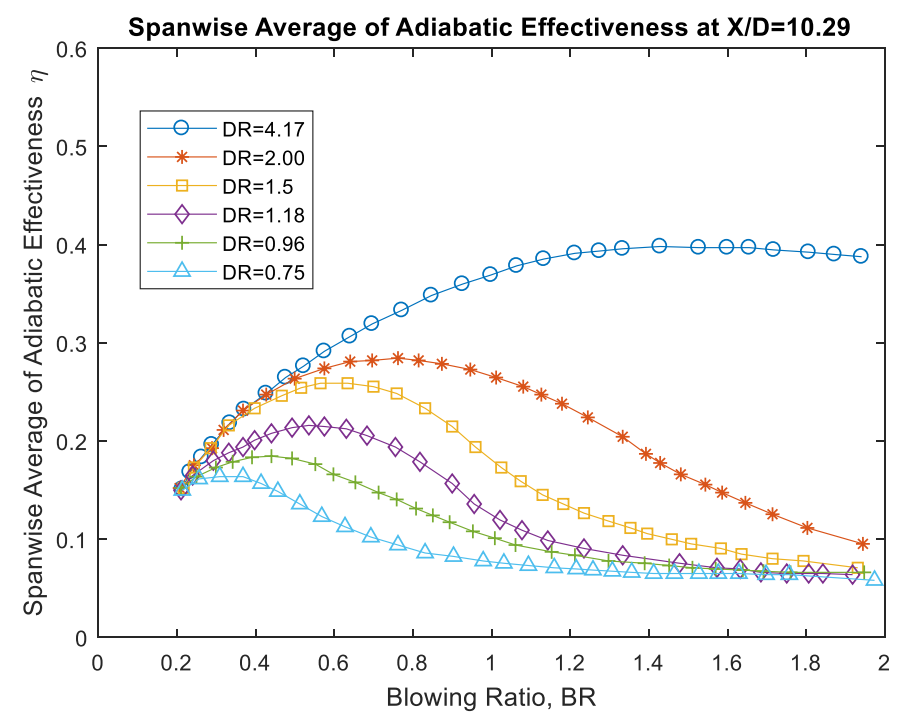

Figure 2: Spanwise averaged effectiveness at a specific distance from the holes, varying DR and BR [9].

Most of the research focuses primarily on the effects of these geometries and various flow conditions with the secondary flow introduced from a plenum located right underneath the film cooling holes, as shown in Figure 3. For this study, this will be referred to as conventional plenum-fed film cooling. 


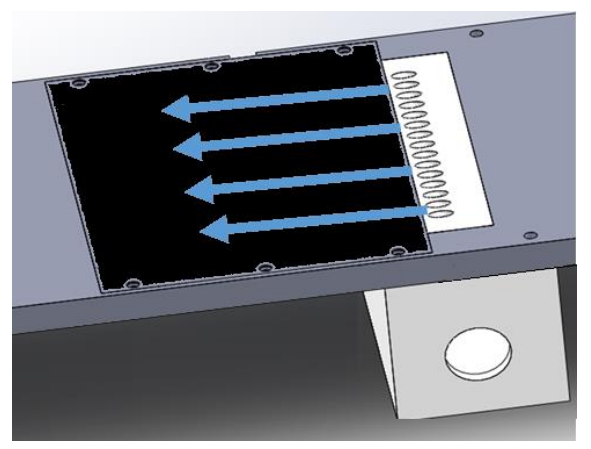

Figure 3: Conventional plenum-fed film cooling

Double-wall cooling is a scheme in which there is external cooling to the hot side of the surface from the film, but also internal cooling to the cold side of the surface. This type of modeling is a more indicative representation of cooling techniques in turbine blades and vanes.

There are various forms of double wall cooling. Cerri et al. [10] discuss advancements in effusive cooling techniques, such as transpiration cooling through porous media and impingement cooling, and geometry such as Lamilloy. Stoakes and Ekkad [11] show a numerical analysis of impingement jets and its effect on heat transfer coefficient. Rogers et al. [12], Ligrani et al. [13], and Ren et al. [14] develop experimental methods to show the effect of double-wall cooling with internal impingement cooling, cross flow cooling, or both feeding the film cool holes on heat transfer coefficient and adiabatic effectiveness, simulating combustor liner conditions. Tan et al. [15] show experimental results for effusive and impingement cooling with short normal injection holes (injection angle at $90 \mathrm{deg}$ ) at turbine inlet flow conditions. Hale et al. [16] compared the effects of plenum flow direction (co-flow and counter-flow) and injection angles. The present study builds on this by focusing on the effect of backside counter-flow cooling on heat transfer coefficient and adiabatic effectiveness with various $\mathrm{DR}, \mathrm{BR}, \mathrm{L} / \mathrm{D}$ ratios, and up to an X/D of 23 with different mainstream Reynolds numbers.

\section{EXPERIMENTAL METHOD}

\section{Rig and Instrumentation}

The rig used in this experiment is a low speed wind tunnel at Virginia Tech. Figures 4 and 5 show an isometric view and the instrumentation, respectively, of the experimental set up.

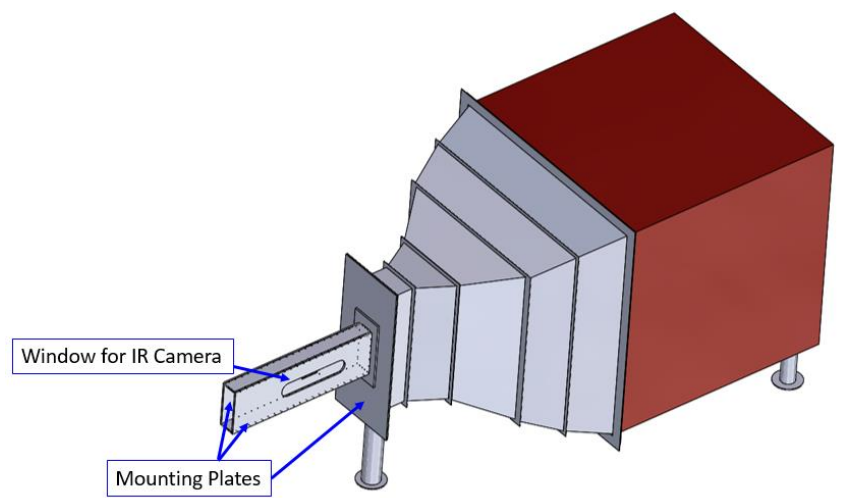

Figure 4: Isometric view of Virginia Tech low speed wind tunnel

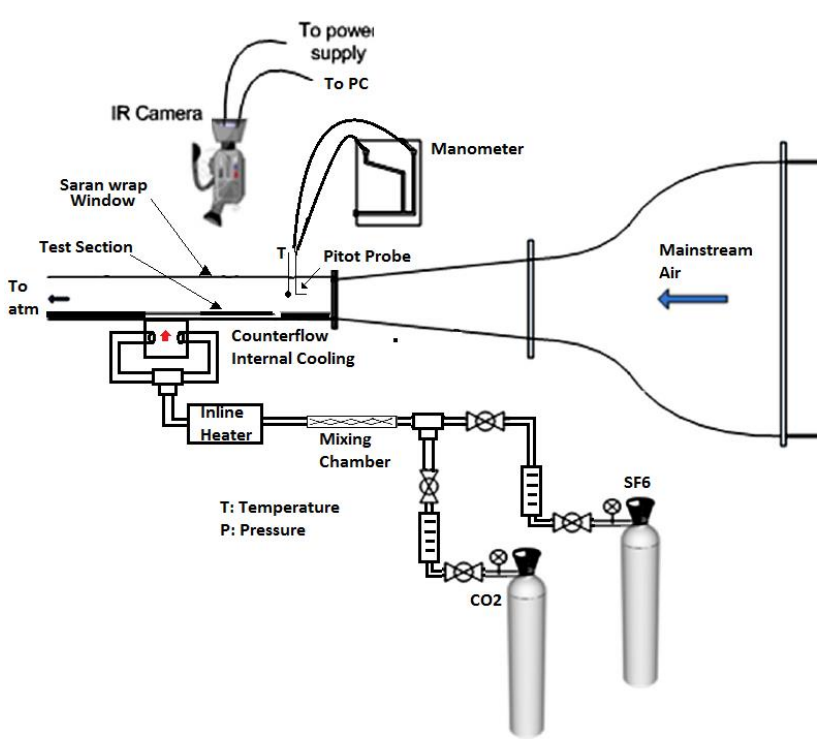

Figure 5: Instrumentation for Virginia Tech low speed wind tunnel

Mainstream air velocity and temperature are measured using a pitot probe and thermocouple, respectively, placed about 6 in. downstream from the leading edge of the tunnel. As can be seen from Figures 4 and 5, the test section is assembled into polycarbonate frames which are then attached to the wind tunnel. The mainstream flow is tripped at about $1 \mathrm{in}$. from the leading edge of the frame and wind tunnel conjunction. A port is left in one side of the polycarbonate plate as a window for infrared (IR) thermography. The window is sealed internally using thin plastic material (Saran wrap).

IR thermography is used to capture temperature images. A FLIR A655SC high resolution IR camera with a FLIR T197922 25 deg. lens is used. The IR images are calibrated with an OMEGA 5SRTC-TT-T-40-36 thermocouple (TC) measuring the surface temperature of the plate. Compressed air and a SF6/CO2 gas mixture are used as coolants in order to match various DR. Although engine conditions produce heat transfer from the mainstream fluid to the wall, a common approach in a lab setting 
is to reverse the heat transfer direction, from the wall outward. Typically, the mainstream fluid is heated to model various density ratios. In this study, an alternate approach, a "heated coolant" method, is used instead of the traditional heated mainstream method due to increased accuracy in temperature control. Similar procedure is used by Hale et al. [16] and Kwak and Han. [17]. This coolant fluid travels through a mixing chamber before entering an $8-\mathrm{kW}$ inline heater, which controls its temperature using an Athena 16C PID controller with a temperature range up to $760^{\circ} \mathrm{C}$. Thin Minco foil heaters $\mathrm{P} / \mathrm{N}$ HK6910 are used to provide a constant heat flux to the plate. This is controlled using auto-transformers TDGC- $0.5 \mathrm{~km}$.

\section{Test Section}

For this study, a proprietary geometry is used to explore the sensitivity of internal cross flow on film performance with short holes. Details of the internal geometry are proprietary and cannot be disseminated but it can be described as a counter flow heat exchanger as coined by Figure 1b in Kirollos and Povey [18]. The test section consists of 3D printed ABS piece with backside cooling, foil heaters, and a thin copper flat plate screwed on top, mounted as an assembly to a polycarbonate frame that connects to the low speed wind tunnel. Figure 6 shows the location of the test section in the assembly. The $\mathrm{S} / \mathrm{D}$ (span/diameter) ratio is maintained at 1.65 , to model turbine component geometric conditions. Data are obtained up to an X/D of 23, where $\mathrm{X}$ is the downstream distance from the holes, as shown in Figure 6.

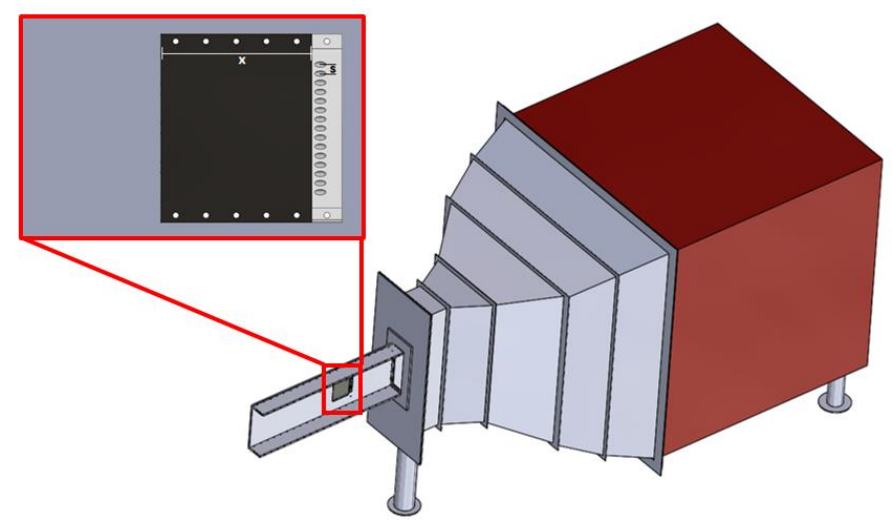

Figure 6: Location of test section in test assembly (window frame removed)

A test section assembly is shown in Figure 7, which highlights the backside counter-flow cooling. For this study, the internal counter-flow test configuration is referred to as the backside cooling (BSC) configuration.

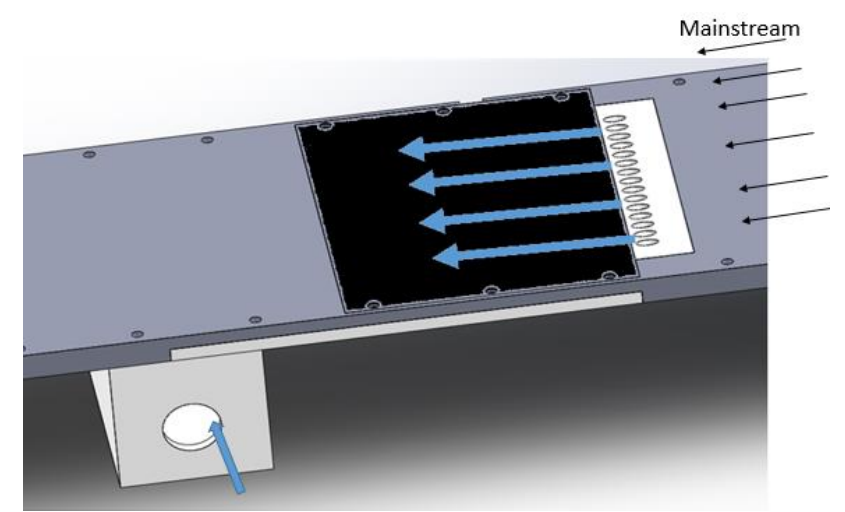

Figure 7: Test section assembly - secondary fluid traveling internally in counter-flow direction before exiting holes

This study also focuses on the effect of unconventional L/D ratios. The previous studies that have been mentioned have an $\mathrm{L} / \mathrm{D}$ ratio that is in the range of 3.5-10. In the present study, the $\mathrm{L} / \mathrm{D}$ ratios are 1 and 2 , with an injection angle of $30 \mathrm{deg}$. A thin wall is preferred so the internal cooling can impact the hot side of the wall.

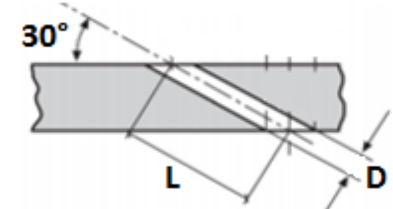

Figure 8: Definition of Length (L) / Diameter (D) ratio

\section{Data Reduction Method}

In previous experiments, such as Ramesh et al. [8], Rogers et al. [12], Ligrani et al. [13], among others, a 1D semi-infinite transient conduction model is used. Due to the low L/D ratios used in this study, coupled with backside cooling, this traditional method is no longer appropriate. The inability to have a transient analysis leads to a steady-state experiment.

There are primarily two quantities of interest in a film cooling experiment, ' $\eta$ ' (adiabatic film cooling effectiveness) and ' $h$ ' (heat transfer coefficient). These two quantities are coupled since ' $h$ ' in film cooling is driven by the film temperature $\left(T_{f}\right)$ which is in turn driven by the specific aerothermal properties of coolant and mainstream air (captured by ' $\eta$ ').

The data reduction procedure is decoupled into two sets of experiments, which the authors refer to as the $h$ and $\eta$ experiments, as seen in Figure 9. The first experiment, called the $\mathrm{h}$ experiment, creates a simplified two temperature problem in which the coolant temperature approximately equals the mainstream temperature. Since the primary and secondary fluid are at the same temperature, any given mix of them will be at the same temperature, which results in a known film temperature, $T_{g}=T_{c}=T_{f}$. In this case, adiabatic effectiveness is undefined. However, this simplification allows the authors to have a known adiabatic wall temperature (film temperature), increasing the signal to noise ratio with the heat transfer coefficient measurement 


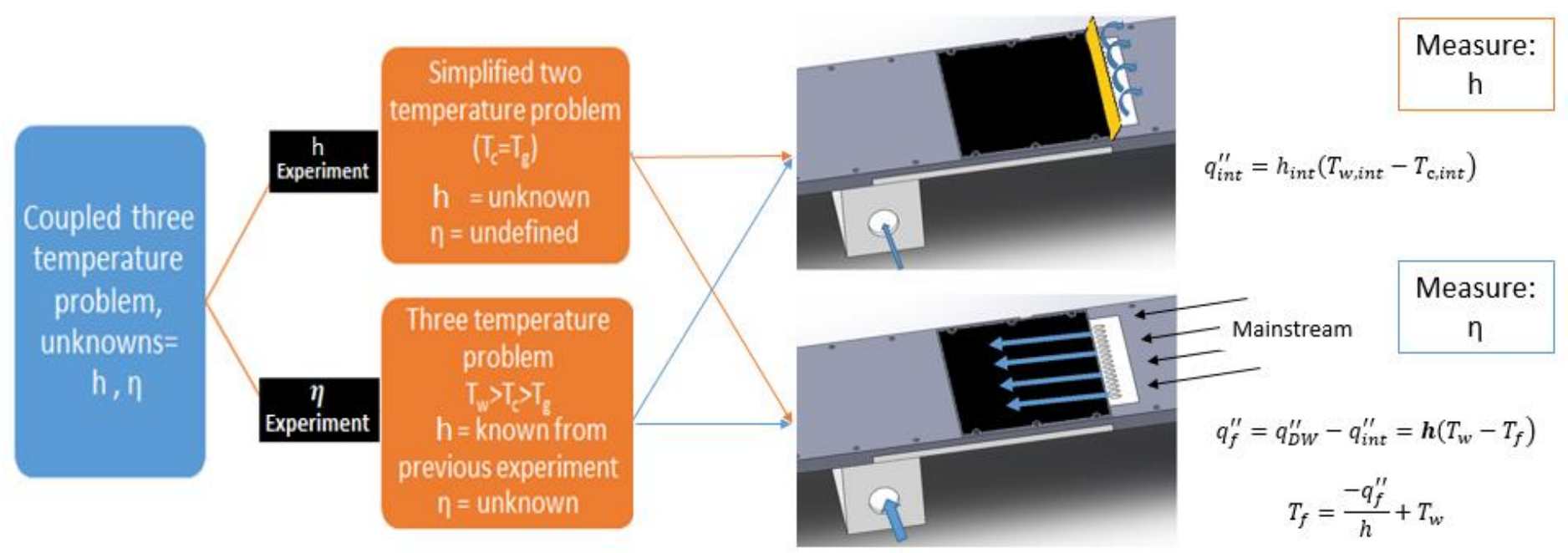

Figure 9: Decoupled experiment in order to improve Signal-to-Noise ratio (SNR)

Since the goal is to characterize heat transfer behavior on the external side, it is important to accurately account for any heat lost on the internal cooling side. In order to do this, this experiment is further divided into two separate cases:

1. Internal backside cooling (subscript 'int')

2. Integrated backside and film cooling (subscript ' $D W$ ')

The first case studies the internal effects only, which include backside cooling and any losses that take place in the test section. There is no mainstream flow and the coolant, as it exits the hole, is diverted away from the test section using a diverter. Equation 4 is used for this internal backside cooling case:

$$
q_{i n t}^{\prime \prime}=h_{\text {int }}\left(T_{w, i n t}-T_{c, i n t}\right)
$$

The wall temperature $T_{w, i n t}$, is measured from the external side of the copper plate using IR thermography. Due to the thin copper plate, the authors assume the internal and external temperatures of the plate to be approximately equal. The heat transfer coefficient $h_{\text {int }}$, is the effective heat transfer coefficient associated with the internal geometry and flow and any associated losses. This experiment yields a relationship (linear) between $q_{\text {int }}^{\prime \prime}$ and $T_{w, i n t}$.

The second case is an integrated backside and film cooling case (double wall cooling). The heat flux associated with the integrated double wall cooling is referred to as $q_{D W}^{\prime \prime}$. The net heat flux, or the heat flux associated with film cooling, $q_{f}^{\prime \prime}$, is then found by subtracting the backside cooling effects, as shown in Equation 5

$$
q_{f}^{\prime \prime}=q_{D W}^{\prime \prime}-q_{i n t}^{\prime \prime}=h\left(T_{w}-T_{f}\right)
$$

The film cooling heat transfer coefficient, $h$, is the slope of Equation 5 and can be seen in Figure 10.

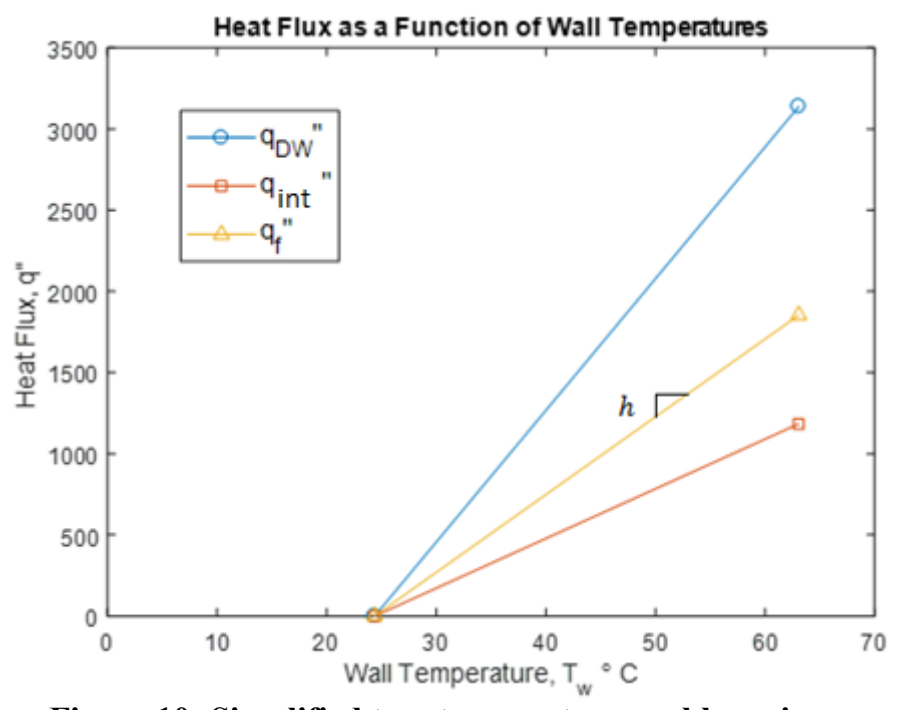

Figure 10: Simplified two-temperature problem gives a known adiabatic wall temperature, increasing the signal-tonoise ratio of heat transfer coefficient measurement

The second experiment, referred to as the effectiveness experiment, is a traditional three-temperature problem. Each of the cases discussed is repeated, but with a heated coolant. Due to the difference between the coolant temperature and the mainstream temperature, the adiabatic wall temperature, $T_{f}$, is unknown. However, a known heat transfer coefficient is used from the previous experiment to calculate adiabatic wall temperature as shown in Equation 6:

$$
T_{f}=-\frac{q_{f}^{\prime \prime}}{h}+T_{w} .
$$

This temperature is then used to find the adiabatic film cooling effectiveness from Equation 1. 
ResearchIR software is used to capture the IR images and MATLAB image processing toolbox is used to calibrate them. Figure 11 shows an example of two images calibrated on one another and ready to be analyzed. Contour plots for heat transfer coefficient and adiabatic effectiveness, which are not shown in this study due to proprietary restrictions, are generated using MATLAB. This study focuses on the results in the middle seven holes of the test section in order to eliminate edge effects.

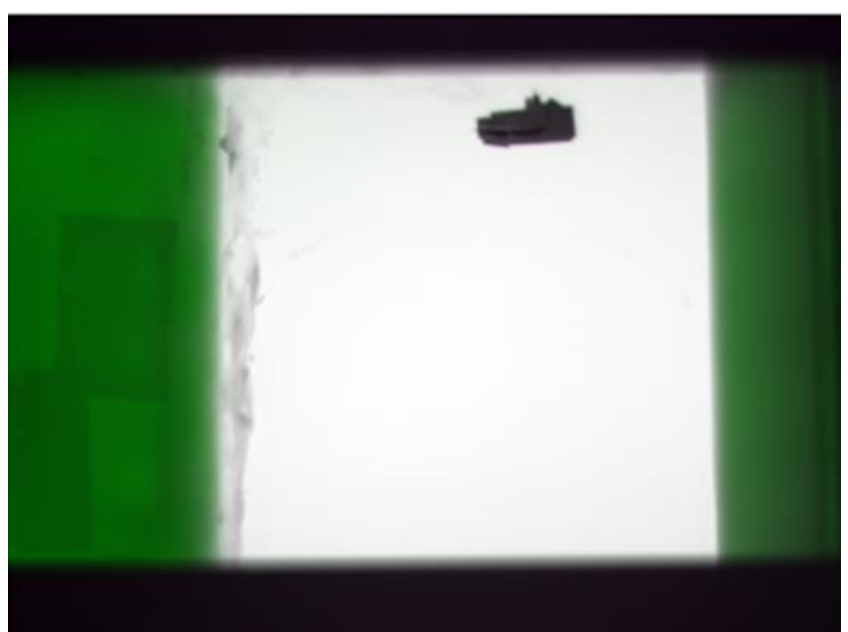

Figure 11: Calibrated images used from the MATLAB images processing toolbox

An uncertainty analysis similar to Cline and McClintock [19] was used. An approximate percent error of $\pm 6 \%$ was found for heat transfer coefficient and \pm 0.09 from the true value for adiabatic effectiveness.

\section{Test Conditions}

The present study consists of finding the effects of various parameters that are included in the table below.

Table 1: Experiment test matrix

\begin{tabular}{|l|l|}
\hline Key Parameter & Value \\
\hline Configuration & $\begin{array}{l}\text { BSC Fed } \\
\text { Plenum Fed }\end{array}$ \\
\hline BR & $0.5,1,1.5$ \\
\hline DR & $0.92,2$ \\
\hline L/D & 1,2 \\
\hline Reynolds Number & 100,000 \\
& 500,000 \\
\hline
\end{tabular}

The effect of backside cooling is compared to results with conventional plenum-fed cooling. A DR of 0.92 was chosen since much of previous relevant research has been done at approximately this condition. The study however, focuses on the results with DR of 2, as this is a better model for engine turbine conditions. The Reynolds numbers chosen is to favor increased turbulence.

\section{EXPERIMENTAL RESULTS \\ Effect of Backside Cooling}

Data were gathered at various BR with both conventional plenum-fed and backside internal cooling configurations. Figure 12 shows the backside cooling effect on adiabatic effectiveness at a Reynolds number $=100,000, \mathrm{~L} / \mathrm{D}=1$ and $\mathrm{DR}=2$. The trend for the plenum-fed cases is consistent with Figure 2, taken from Ekkad and Han [9].

Backside cooling has a higher effectiveness than a plenumfed case at the conditions shown. Additionally, with varying BR, the backside cooling cases have an opposite trend to the ones found with plenum-fed cases. In other words, the peak effectiveness with backside cooling is found at a lower BR and effectiveness decreases with increasing BR. This trend is also found in Tan et al. [15] in their effusion cooling results with short normal injection holes and in Hale et al. [16] in their counterflow cooling results near the holes.

This result shows that the flow distribution as the coolant exits the hole is different than in the plenum-fed cases. This can also be seen from the heat transfer coefficient measurements in Figure 13, which show that heat transfer coefficients corresponding to the film cooling in the external side of the plate is larger with backside cooling than with plenum-fed cooling.

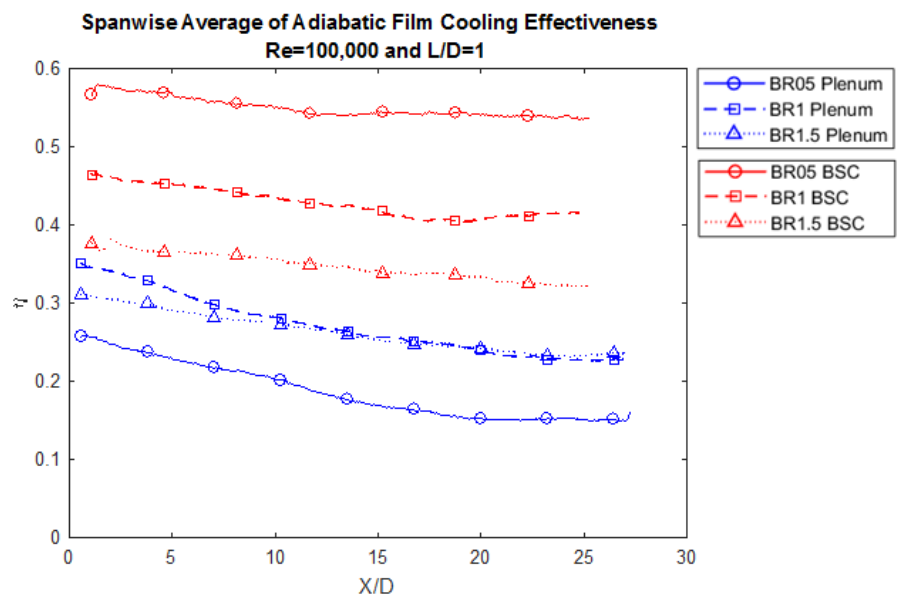

Figure 12: Effect of backside cooling on adiabatic effectiveness at $R e=100,00, L / D=1, D R=2$ with varying $B R$ 


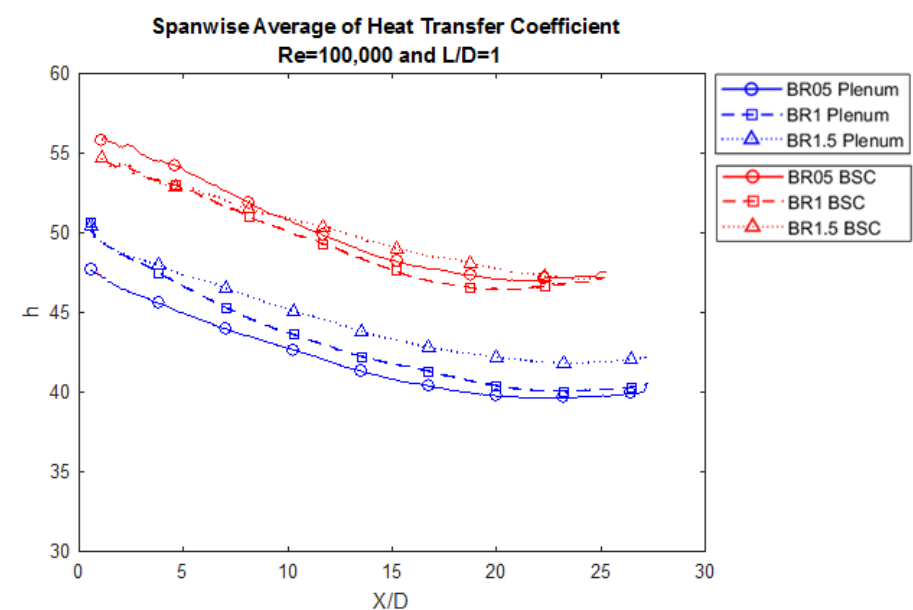

Figure 13: Effect of backside cooling on heat transfer coefficient at $R e=100,000, L / D=1, D R=2$ with varying $B R$

\section{Effect of Density Ratio}

Compressed air and a $\mathrm{SF} 6 / \mathrm{CO} 2$ gas mixture are used to simulate different DR. Figure 14 shows the effect of DR on adiabatic effectiveness for a specific set of conditions. A higher effectiveness was found with higher DR for all BR cases tested. This trend also matches the results from Ekkad and Han [9].

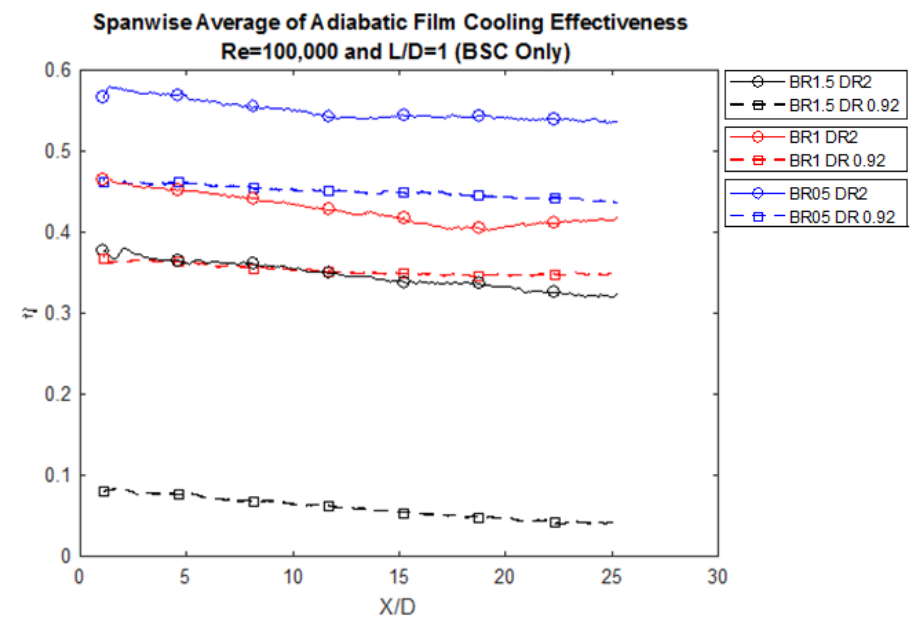

Figure 14: Effect of $D R$ on adiabatic effectiveness at $R e=100,000, L / D=1$, with backside cooling and varying $B R$

Figure 15 shows the DR effect on HTC. In both figures, the DR effect is dependent on the BR. Increasing the BR results in an increasing effect of the DR.

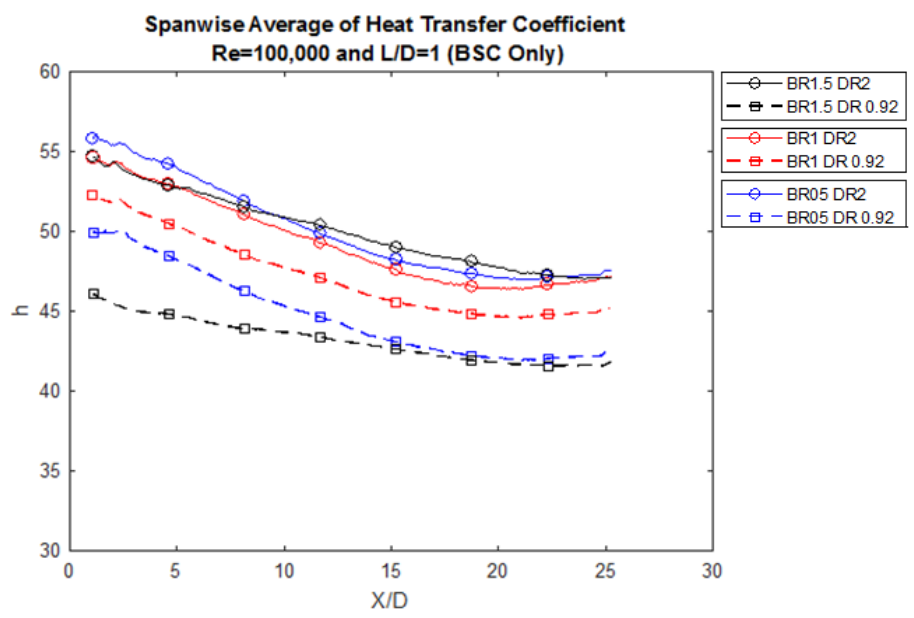

Figure 15: Effect of DR on heat transfer coefficient at $R e=100,000, L / D=1$, with backside cooling and varying $B R$

This can be attributed to the lift off that is occurring at a higher $\mathrm{BR}$. Another way to analyze these figures is to introduce the momentum flux ratio in Equation 7:

$$
I=\frac{\left(\rho U^{2}\right)_{\text {coolant }}}{\left(\rho U^{2}\right)_{\text {mainstream }}}
$$

Another more useful definition of momentum flux ratio is Equation 8:

$$
I=\frac{B R^{2}}{D R}
$$

Table 2 shows the momentum flux ratio for the different combinations shown in Figure 14.

Table 2: Momentum flux ratio for Figures 13 and 14 BR and DR combinations

\begin{tabular}{|l|l|l|}
\hline BR & DR & I \\
\hline $\mathbf{1 . 5}$ & 2 & 1.125 \\
\hline $\mathbf{1 . 5}$ & 1 & 2.25 \\
\hline $\mathbf{1}$ & 2 & 0.5 \\
\hline $\mathbf{1}$ & 1 & 1 \\
\hline $\mathbf{0 . 5}$ & 2 & 0.125 \\
\hline $\mathbf{0 . 5}$ & 1 & 0.25 \\
\hline
\end{tabular}

Table 2 shows that best adiabatic effectiveness is reached with the BR and DR combination that results in the lowest momentum flux ratio. At a constant $\mathrm{BR}$, increasing $\mathrm{DR}$ decreases momentum, which makes it more probable for film attachment. In contrast, increasing momentum will lead to a decrease in adiabatic effectiveness due to lift-off of the coolant.

\section{Effect of L/D Ratio}

Figures 16 and 17 are similar to Figures 12 and 13 but now $\mathrm{L} / \mathrm{D}=2$. The results for this case are similar to the $\mathrm{L} / \mathrm{D}=1$ case. Figures 16 and 17 show that BSC configuration results in a 
higher adiabatic effectiveness and heat transfer coefficient than the plenum-fed configuration. In the plenum-fed case, effectiveness increases with increasing BR, whereas the backside cooling case, this trend is reversed.

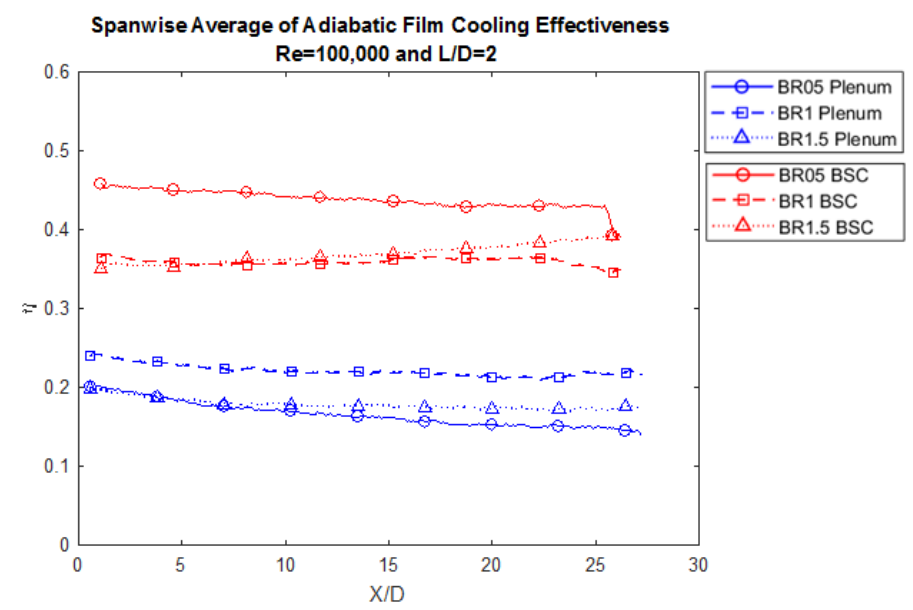

Figure 16: Effect of backside cooling on adiabatic effectiveness at $R e=100,000, L / D=2, D R=2$ with varying $B R$

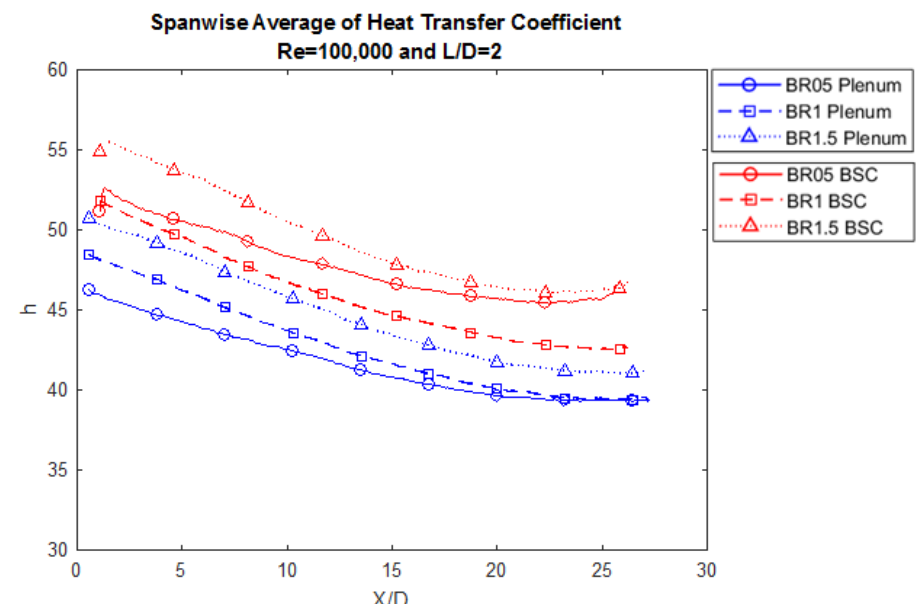

Figure 17: Effect of backside cooling on heat transfer coefficient at $R e=100,000, L / D=2, D R=2$ with varying $B R$

The results show that at $\mathrm{L} / \mathrm{D}=2$, the flow is underdeveloped, similar to the $\mathrm{L} / \mathrm{D}=1$ case, as it comes out of the coolant hole. Lutum and Johnson [20] did a study on effectiveness using various L/D ratios between 1.75-17 and found that effectiveness decreases with decreasing $\mathrm{L} / \mathrm{D}$ ratio in the range $1.75 \leq \mathrm{L} / \mathrm{D} \leq 5$. In the present study however, it was found that the L/D effect is negligible since the differences are sufficiently small to be within the uncertainty of the reduction procedure. The negligible differences lead one to believe that the coolant flow as it exits the holes is similar for the two L/D ratios, both underdeveloped.

\section{Effect of Reynolds Number}

Figures 18 and 19 show the effect of Reynolds number (Re). The study focuses on the effect of turbulent flow on the adiabatic effectiveness and heat transfer coefficient.

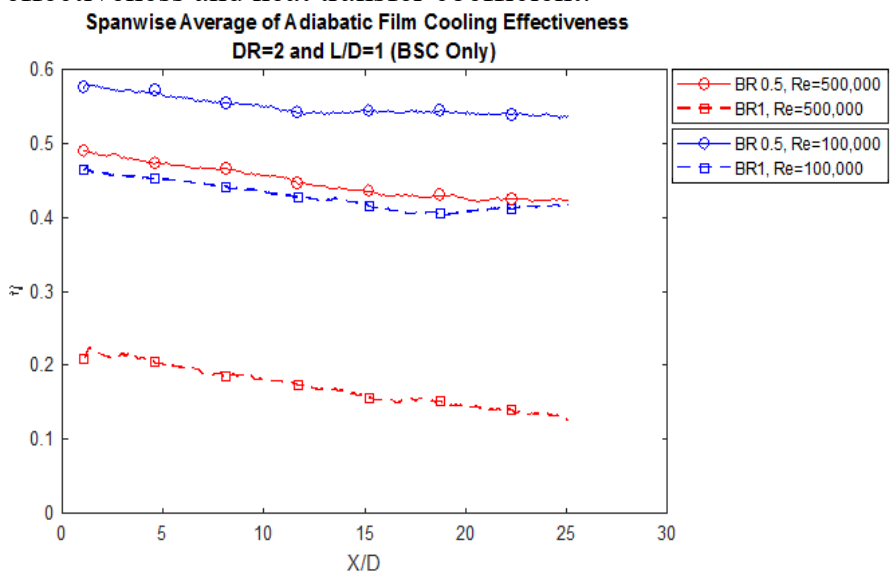

Figure 18: Effect of Reynolds number on effectiveness with $\mathrm{DR}=2$ and $\mathrm{L} / \mathrm{D}=1$ (BSC Only)

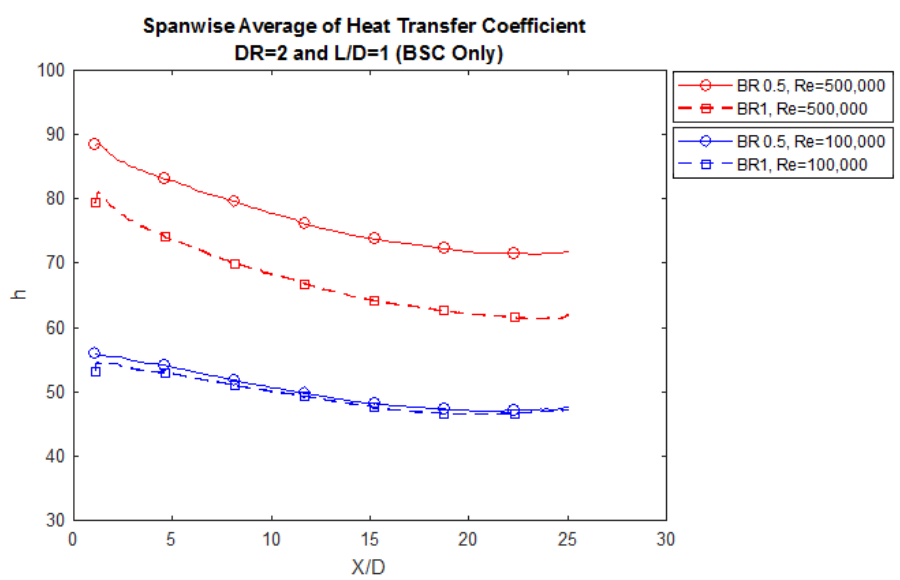

Figure 19: Effect of Reynolds number on heat transfer coefficient with $D R=2$ and a $L / D=1$ (BSC Only)

Only low BR was used as comparison, as it can be seen from previous results that larger BR would lead to higher jet lift-off. At high Re, it was also seen that peak effectiveness was found at a lower BR. Figure 18 shows that increasing Re to a turbulent range decreases the adiabatic effectiveness. This result is due to the external forced flow dominating the energy transfer. Figure 19 shows the expected result of increasing HTC with Re.

\section{CONCLUSIONS}

The present study focuses on the effect of internal backside counter-flow cooling combined with film cooling, using different density, blowing, and length to diameter ratios, and Reynolds numbers. The first and primary study compares the backside cooling (BSC) configuration with a traditional plenumfed configuration at the same flow conditions.

It was found that the incorporation of backside cooling has an effect on adiabatic film cooling effectiveness and heat transfer coefficient. At the baseline $\mathrm{BR}=0.5$, adiabatic effectiveness 
doubled with the BSC configuration while the heat transfer coefficient increased about $10 \%$. In addition, varying BR with all others conditions fixed, the BSC configuration had an opposite trend in effectiveness than the plenum-fed case. This result was seen with two separate $\mathrm{DR}$ and $\mathrm{L} / \mathrm{D}$ ratios and is also seen in Tan et al. [15] and Hale et al. [16]. Yarn flow visualization tests show that the flow exiting the holes with BSC are significantly different from the plenum-fed cases at the same conditions. Introducing counter-flow BSC cooling, the flow is not turning due to the low $\mathrm{L} / \mathrm{D}$ ratio, and thus the flow has a negative $\mathrm{x}$-momentum as it exits the hole or might even travel in other directions, including laterally. In addition, flow in the BSC configuration may be creating a stagnation region, located underneath the film cooling holes, that increases with increasing BR. Due to the low L/D ratios, there is a possibility that the stagnation region may be blocking the holes, resulting in a higher BR that is measured using the flow meters. This hypothesis explains the reverse in trend found in this configuration.

The study also found the effect of DR on adiabatic effectiveness and heat transfer coefficient with the BSC configuration. The results show that increasing DR increases both adiabatic effectiveness and heat transfer coefficient. Increasing DR decreases the momentum flux and makes the coolant more likely to attach to the surface, creating the protective film.

The $\mathrm{L} / \mathrm{D}$ ratio effect was also investigated with a $\mathrm{BSC}$ configuration. Lutum and Johnson [20] show in their study that the coolant flow is underdeveloped below a $\mathrm{L} / \mathrm{D}=5$. Since the differences in the results shown for the two ratios in this study are within the uncertainty of the experiment, no conclusions can be made at this time for the effect of $\mathrm{L} / \mathrm{D}$ ratio.

Finally, the increase in turbulence in the mainstream flow resulted in a decrease of adiabatic effectiveness and an increase in heat transfer coefficient. The decrease in effectiveness is attributed to the external flow dominating energy transfer from the wall.

The authors recommend testing with larger $\mathrm{L} / \mathrm{D}$ ratios in order to compare internal double wall cooling effects with published papers. In addition, the authors recommend future testing at lower BR to find the peak effectiveness with BSC configurations.

\section{NOMENCLATURE}

$\begin{array}{cl}\eta & \text { Adiabatic film cooling effectiveness } \\ T_{g} & \text { Mainstream fluid temperature } \\ T_{f} & \text { Adiabatic wall temperature } \\ T_{c} & \text { Coolant temperature } \\ T_{w} & \text { Wall temperature } \\ U_{g} & \text { Mainstream velocity } \\ U_{c} & \text { Coolant velocity } \\ \text { TIT } & \text { Turbine inlet temperature } \\ \text { DR } & \text { Density ratio } \\ \text { BR } & \text { Blowing ratio } \\ \text { h } & \text { Heat transfer coefficient }\end{array}$

$\begin{array}{cl}\text { IR } & \text { Infrared } \\ \text { TC } & \text { Thermocouple } \\ \text { L } & \text { Diagonal length of film cool hole } \\ \text { D } & \text { Diameter of film cool hole } \\ \text { BSC } & \text { Backside cooling } \\ \text { S } & \text { Spacing between holes } \\ q_{i n t}^{\prime \prime} & \text { Heat flux due to backside (internal) } \\ & \text { cooling only } \\ q_{D W}^{\prime \prime} & \text { Heat flux from double wall cooling } \\ q_{f}^{\prime \prime} & \text { Heat flux from film cooling }\end{array}$

\section{ACKNOWLEDGMENTS}

The authors wish to acknowledge Rolls Royce Corporation in Indianapolis, IN for their support and sponsorship.

\section{REFERENCES}

[1] Yin F, Tiemstra FS, Gangoli Rao. 2018. "A. Development of a Flexible Turbine Cooling Prediction Tool for Preliminary Design of Gas Turbines.” J. Eng. Gas Turbines Power. ():

[2] Goldstein, R. J., 1971, "Film Cooling," Advances in Heat Transfer, Academic Press, San Diego, Vol. 7, pp. 595-607

[3] Bogard, D. G., \& Thole, K. A., 2006, "Gas Turbine Film Cooling," Journal of Propulsion and Power, 22(2), 249-270.

[4] Saumweber, C., Schulz, A., 2012, "Effect of Geometry Variations on the Cooling Performance of Fan-Shaped Cooling Holes." Journal of Turbomachinery, ;134(6):061008-06100816.

[5] Bunker R.S., 2005, “A Review of Shaped Hole Turbine Film-Cooling Technology." Journal of Heat Transfer. 127(4):441-453.

[6] Haven, B. A., \& Kurosaka, M., 1997, "Kidney and AntiKidney Vortices in Crossflow Jets". Journal of Fluid Mechanics, 352, 27-64.

[7] Haven BA, Yamagata DK, Kurosaka MM, Yamawaki SS, Maya TT. 1997. "Anti-Kidney Pair of Vortices in Shaped Holes and Their Influence on Film Cooling Effectiveness," Turbo Expo: Power for Land, Sea, and Air, Volume 3: Heat Transfer; Electric Power; Industrial and Cogeneration ():V003T09A007.

[8] Ramesh, Sridharan, Ramirez, David G., Ekkad, Srinath V., Alvin, Mary A., "Analysis of Film Cooling Performance of Advanced Tripod Hole Geometries With and Without Manufacturing Features," International Journal of Heat and Mass Transfer, Volume 94, 2016, Pages 9-19, ISSN 0017-9310,

[9] Ekkad S, Han J., 2013, "A Review of Hole Geometry and Coolant Density Effect on Film Cooling." Heat Transfer Summer Conference, Volume 3: Gas Turbine Heat Transfer; Transport Phenomena in Materials Processing and Manufacturing V003T20A003.

[10] Cerri G, Giovannelli A, Battisti L, Fedrizzi R. 2007. "Advances in Effusive Cooling Techniques of Gas Turbines," Applied Thermal Engineering, 27(4), p.04692698

[11] Stoakes P, Ekkad S. "Optimized Impingement Configurations for Double Wall Cooling Applications." Turbo 
Expo: Power for Land, Sea, and Air, Volume 5: Heat Transfer, Parts $A$ and $B(): 1535-1543$.

[12] Rogers N, Ren Z, Buzzard W, et al. 2017, "Effects of Double Wall Cooling Configuration and Conditions on Performance of Full-Coverage Effusion Cooling." J. Turbomach. 2017;139(5):051009-051009-13.

[13] Ligrani P, Ren Z, Liberatore F, Patel R, Srinivasan R, Ho Y. 2017, "Double Wall Cooling of a Full-Coverage Effusion Plate, Including Internal Impingement Array Cooling." J. Eng. Gas Turbines Power. 2017;140(5):051901-051901-9.

[14] Ren, Z., Vanga, S. R., Rogers, N., Ligrani, P., Hollingsworth, K., Liberatore, F., . . . Ho, Y. 2017. "Internal and External Cooling of a Full Coverage Effusion Cooling Plate: Effects of Double Wall Cooling Configuration and Conditions," International Journal of Thermal Sciences, 124, 36-49.

[15] Tan X, Zhang J, Xu H. 2015. "Experimental Investigation on Impingement/Effusion Cooling with Short Normal Injection Holes," International Communications in Heat and Mass Transfer. 69 p1-10.

[16] Hale C. A., Plesniak M. W., Ramadhyani S. 2000. "Film Cooling Effectiveness for Short Film Cooling holes Fed by a Narrow Plenum,”. J. Turbomachinery 122(3): 553-557

[17] Kwak J, Han J. 2003. "Heat Transfer Coefficients and Film Cooling Effectiveness on the Squealer Tip of a Gas Turbine Blade,". J. Turbomach. 125(4):648-657.

[18] Kirollos B, Povey T. 2014, "Reverse-Pass Cooling Systems for Imptoved Performance," J. Turbomachinery; 136(11)

[19] Kline, S. J., and McClintock, F. A., "Describing Uncertainties in Single Sample Experiments," Mech. Eng. (Am. Soc. Mech. Eng.) 75 (1953) 3-8.

[20] Lutum EE, Johnson BV. 1999, "Influence of the Hole Length-to-Diameter Ratio on Film Cooling With Cylindrical Holes.” J. Turbomach.; 121(2):209-216. 


\section{ANNEX A}

\section{LIST OF FIGURES}

Figure 1: Film cooling over a flat plate. Secondary (coolant) fluid introduced to cool external surface..................................2

Figure 2: Spanwise averaged effectiveness at a specific distance from the holes, varying DR and BR [9].......................... 2

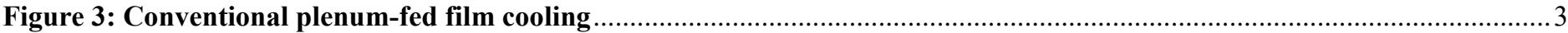

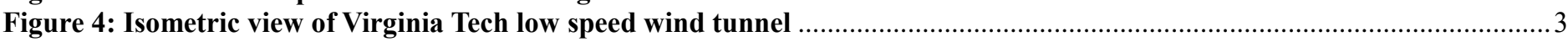

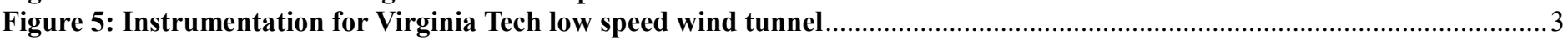

Figure 6: Location of test section in test assembly (window frame removed).........................................................

Figure 7: Test section assembly - secondary fluid traveling internally in counter-flow direction before exiting holes ................. 4

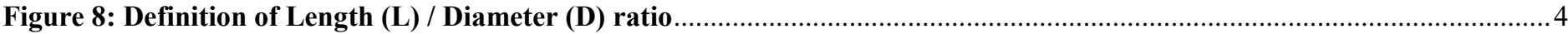

Figure 9: Decoupled experiment in order to improve Signal-to-Noise ratio (SNR) ..................................................... 5

Figure 10: Simplified two-temperature problem gives a known adiabatic wall temperature, increasing the signal-to-noise ratio

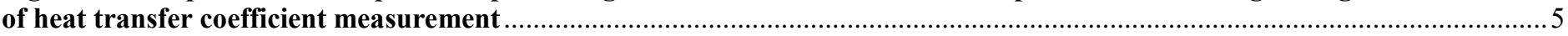

Figure 11: Calibrated images used from the MATLAB images processing toolbox ........................................................... 6

Figure 12: Effect of backside cooling on adiabatic effectiveness at $R=100,00, L / D=1, D R=2$ with varying $B R \ldots \ldots \ldots \ldots \ldots \ldots \ldots .6$

Figure 13: Effect of backside cooling on heat transfer coefficient at $R=100,000, L / D=1, D R=2$ with varying $B R \ldots \ldots \ldots \ldots \ldots \ldots .7$

Figure 14: Effect of $D R$ on adiabatic effectiveness at $R e=100,000, L / D=1$, with backside cooling and varying $B R \ldots \ldots \ldots \ldots \ldots \ldots .7$

Figure 15: Effect of $D R$ on heat transfer coefficient at $R e=100,000, L / D=1$, with backside cooling and varying $B R \ldots \ldots \ldots \ldots \ldots .7$

Figure 16: Effect of backside cooling on adiabatic effectiveness at $R e=100,000, L / D=2, D R=2$ with varying $B R \ldots \ldots \ldots \ldots \ldots \ldots . .8$

Figure 17: Effect of backside cooling on heat transfer coefficient at $R=100,000, L / D=2, D R=2$ with varying $B R \ldots \ldots \ldots \ldots \ldots \ldots .8$

Figure 18: Effect of Reynolds number on effectiveness with $D R=2$ and a $L / D=1$ (BSC Only) ....................................... 8

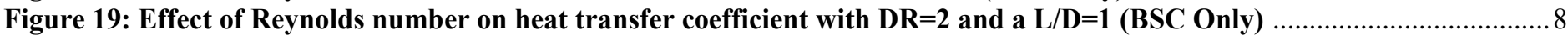

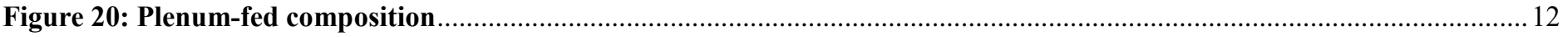

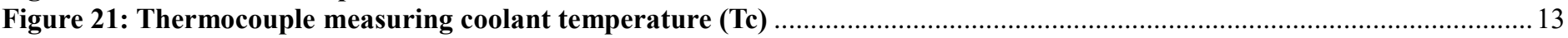

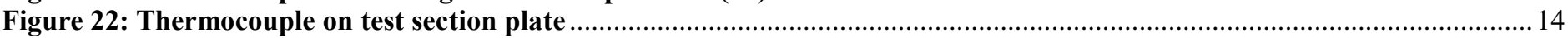

Figure 23: Position of camera at an angle to prevent reflection................................................................................. 15

Figure 24: Stagnant air potentially blocking film cooling holes, leading to increase in exit velocity and BR ........................ 17 


\section{ANNEX B \\ DETAILED GEOMETRY OF TEST SECTION}

The test section itself is composed of a 3D-printed ABS piece, foil heaters to model uniform heat flux, and a thin copper plate as shown in Figure 20. This assembly is then mounted in the mounting frames as is shown in Figure 7. The geometry of the test section was varied in order to study the effects of the introduction of backside counter-flow cooling configuration as well as the L/D ratio. The table below shows the 4 geometries that were used in this study:

Table 3: Geometries used in this study

\begin{tabular}{|l|l|l|}
\hline Geometry & Configuration & L/D \\
\hline $\mathbf{1}$ & Backside Cooling (BSC) & 1 \\
\hline $\mathbf{2}$ & Backside Cooling (BSC) & 2 \\
\hline $\mathbf{3}$ & Plenum-fed & 1 \\
\hline $\mathbf{4}$ & Plenum-fed & 2 \\
\hline
\end{tabular}

The focus of this study is to compare the results of adiabatic film cooling effectiveness and heat transfer coefficient with backside cooling counter-flow cooling and plenum-fed film cooling. It is important to note that the purpose of Figure 20 is to show the subassembly of the test section. An accurate figure of the 3D-printed ABS piece cannot be shown due to proprietary restrictions.
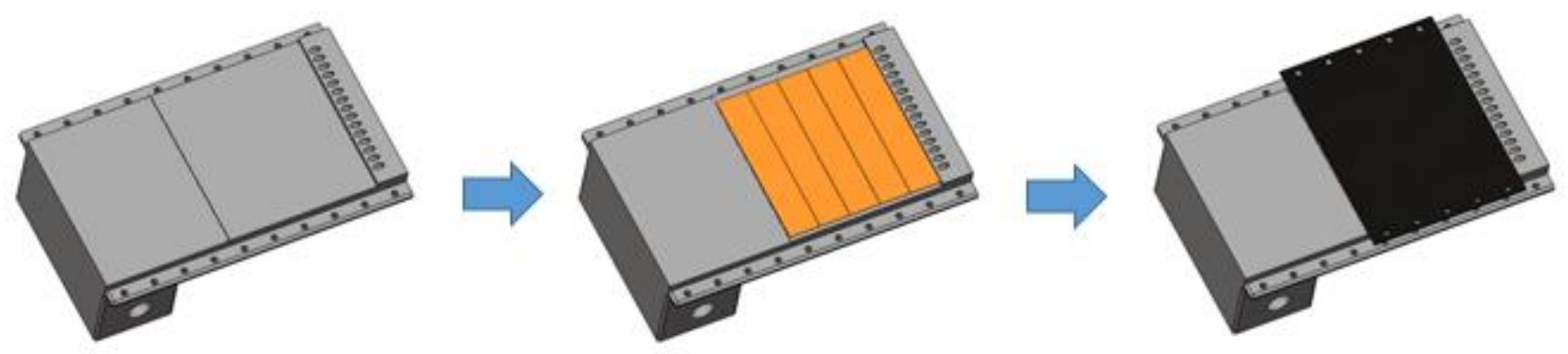

Figure 20: Plenum-fed composition 


\section{ANNEX B}

\section{DETAILS ON INSTRUMENTATION}

Figure 5 shows the instrumentation used in this study. The mainstream air is controlled through the motor frequency controller on the wind tunnel. The velocity and temperature of the mainstream air are measured through a pitot probe and thermocouple, respectively, that are placed approximately 6 inches from the leading edge of the frames that attach to the wind tunnel. Air and a SF6/CO2 gas mixture are used for the secondary fluid, also known as the cooling fluid, to match the different DR. The BR is controlled using valves and flow meters. Pressure and temperature measurements are made to calibrate the measurements for the different gases used. The coolant fluid enters a mixing chamber that is made up of a 1-foot-long pipe with metal scrubbers, before entering an inline heater. It is then routed to both sides of the plenum on the test section via insulated rubber hoses. The coolant temperature is measured by inserting a thermocouple through the test section from underneath as seen in Figure 21. Since the middle 7 holes are the area of interest, the thermocouple was placed near the top of the test section. It is important to note that Figure 21 has been edited to make sure any internal geometry is not seen, to protect proprietary information.

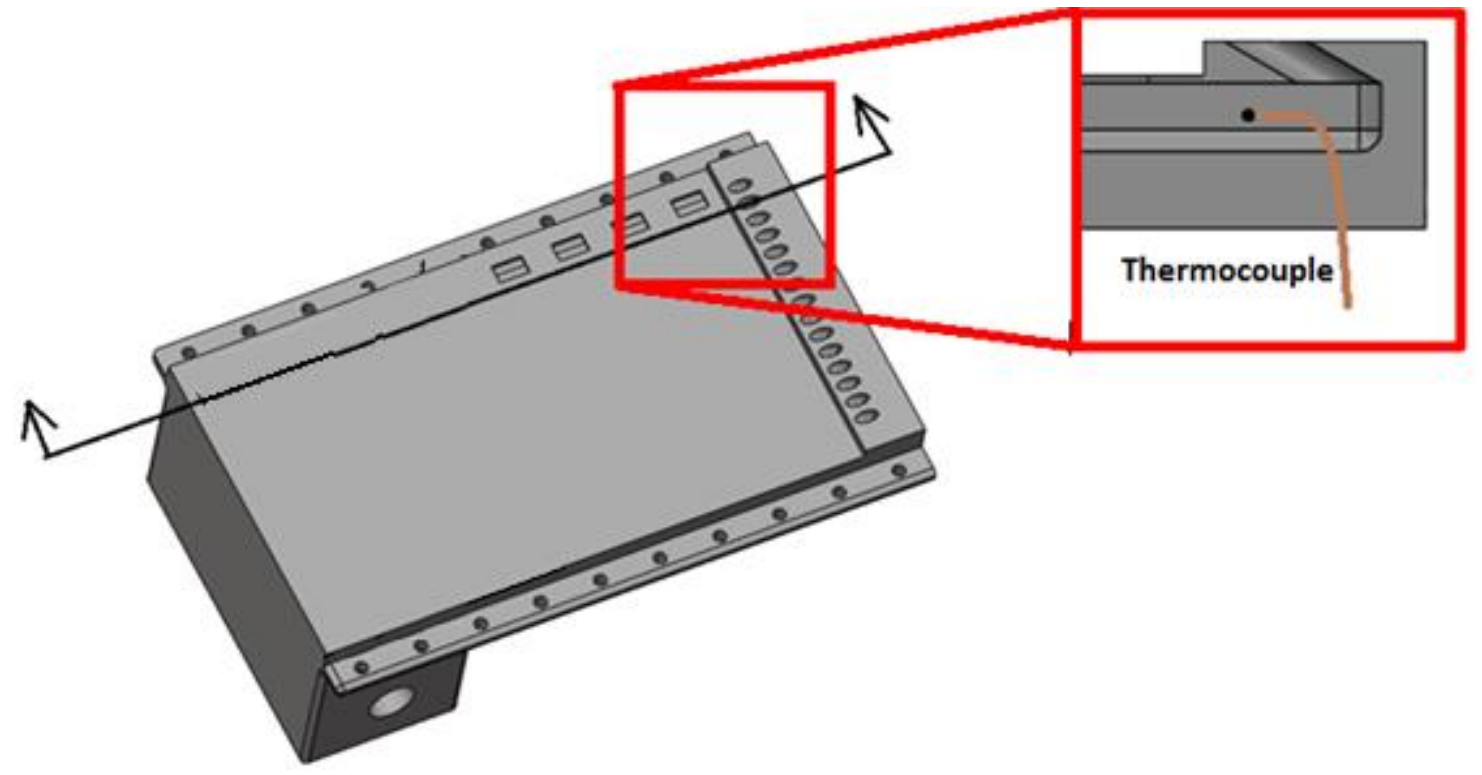

Figure 21: Thermocouple measuring coolant temperature (Tc)

A thermocouple is also placed on the test plate surface to calibrate the IR camera readings. Since the experiments are measured at steady state, only 1 thermocouple was used. In addition, the thermocouple was placed in the upper quarter of the test section as seen in Figure 22, in order to not interfere with the area of interest, which are the middle 7 holes. 


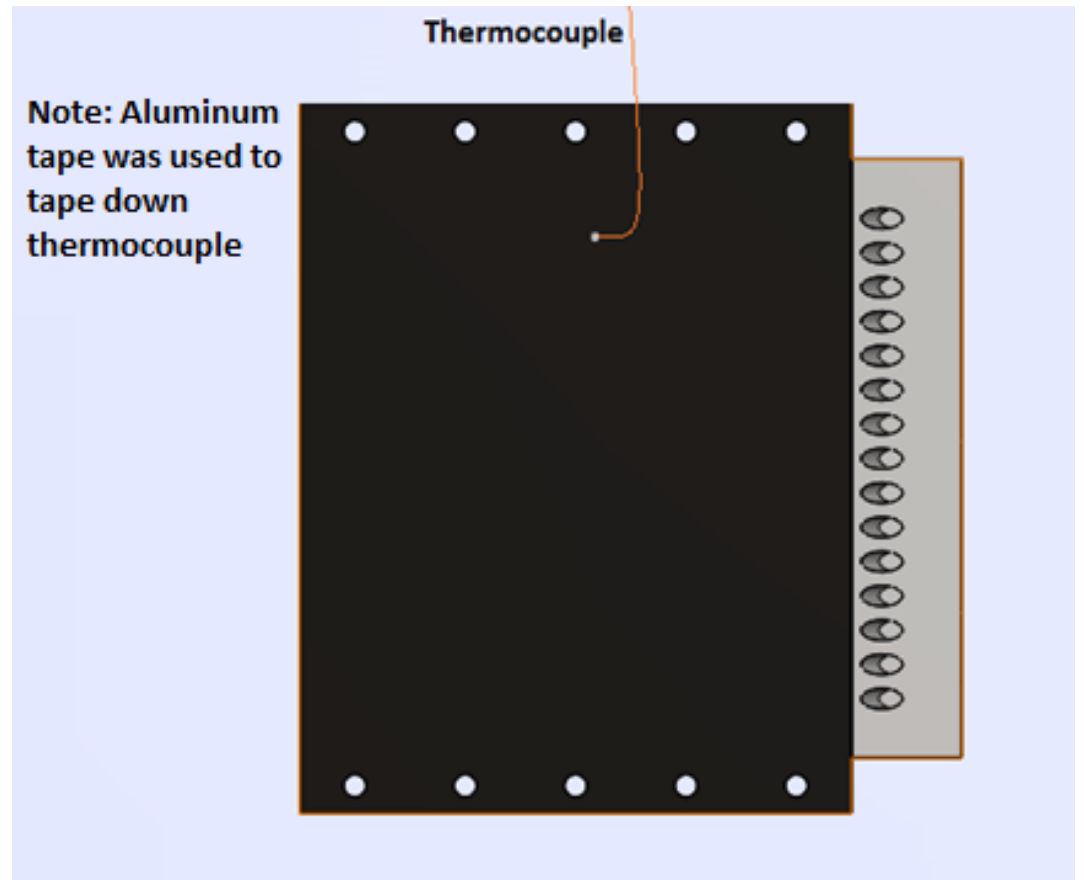

Figure 22: Thermocouple on test section plate 


\section{ANNEX C}

\section{IR THERMOGRAPHY}

It is seen from Figure 23 that a window was cut in the frame to be used as a window for the IR camera readings. The window is sealed internally using plastic wrap. A FLIR A655SC high resolution camera is mounted on a tripod and is placed at an angle facing the test section. It is placed at an angle in order to avoid the camera's reflection which would affect the temperature reading.

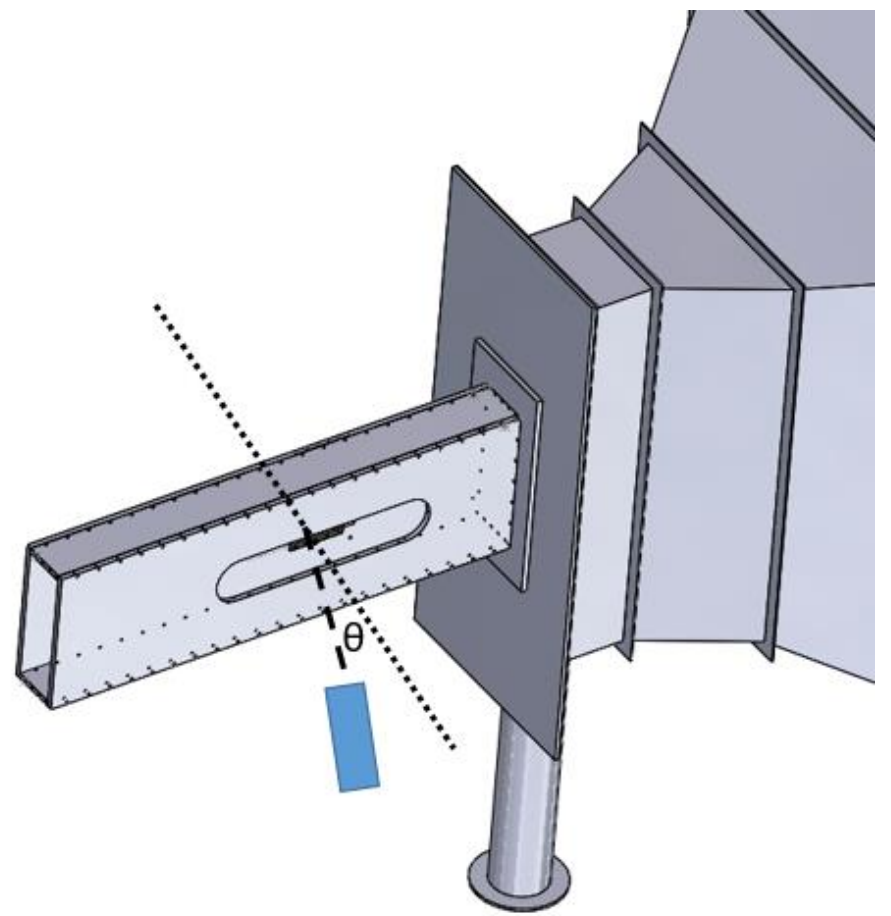

Figure 23: Position of camera at an angle to prevent reflection

The focus of the camera and image capturing is done through the ResearchIR software. All the data points (images) captured must be calibrated to the same spatial position in order to analyze pixel by pixel. This image calibration is done using the image processing toolbox found in MATLAB as can be seen in Figure 11 


\section{ANNEX D \\ DATA REDUCTION PROCEDURE DETAILS}

The data reduction procedure is explained in the section with the same name in the main part of this paper. A more detailed explanation is shown here. As mentioned, the procedure involves decoupling into two sets of experiments: HTC experiment and $\eta$ experiment.

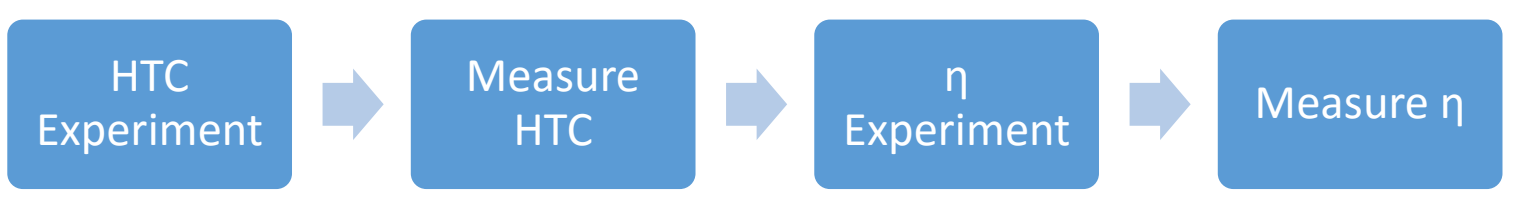

In order to find the film cooling parameters, the internal cooling effect and losses must be taken into account. Each experiment is further decoupled into 2 separate cases as can be read in the Data Reduction Method section of this paper.

Decoupling into two sets of experiments increases the signal to noise ratio (SNR). The HTC experiment is done at ambient conditions, meaning that the coolant flow and the mainstream flow are at approximate the same temperature. The coolant picks up energy (heat) as it travels internally. As can be seen from Annex B, Tc is measured as the temperature as the flow exits the hole. However, the temperature difference between the mainstream and the coolant is small enough $(\sim 2 \mathrm{C}-5 \mathrm{C})$ that a film temperature can be calculated by taking the average of these two temperatures. Knowing the film temperature increases our signal to noise ratio and increases the confidence for a more accurate HTC measurement.

The $\eta$ experiment repeats the cases in the HTC experiment but with a heated coolant. The film temperature is unknown in this case, but it is solved for using a known HTC from the previous experiment. 
ANNEX E

\section{DETAILS ON BSC RESULT HYPOTHESIS}

It was found that varying BR with BSC configuration has an opposite trend in effectiveness than a conventional plenum-fed case. Backside cooling is done in an internal counter-flow fashion. As the flow exits the hole, the flow may be coming out in various directions, including laterally before being carried by the mainstream flow into the test section plate. This is known as slot film cooling. It is seen that low BR creates the best effectiveness, a different result than the plenum-fed case. The counter flow may hit the wall and create a space of stagnant air right underneath the film cool holes. The space that the stagnant air takes up increases with increasing BR. As can be seen in the figure below, the increasing space of stagnant air may be blocking the holes themselves, due to the very low L/D ratios. The potential blockage decreases the effective exit area, increasing the exit velocity of the coolant and the BR. The hypothesis states that effective BR is larger than the measured BR, leading to jet lift off of the coolant, decreasing the adiabatic effectiveness.

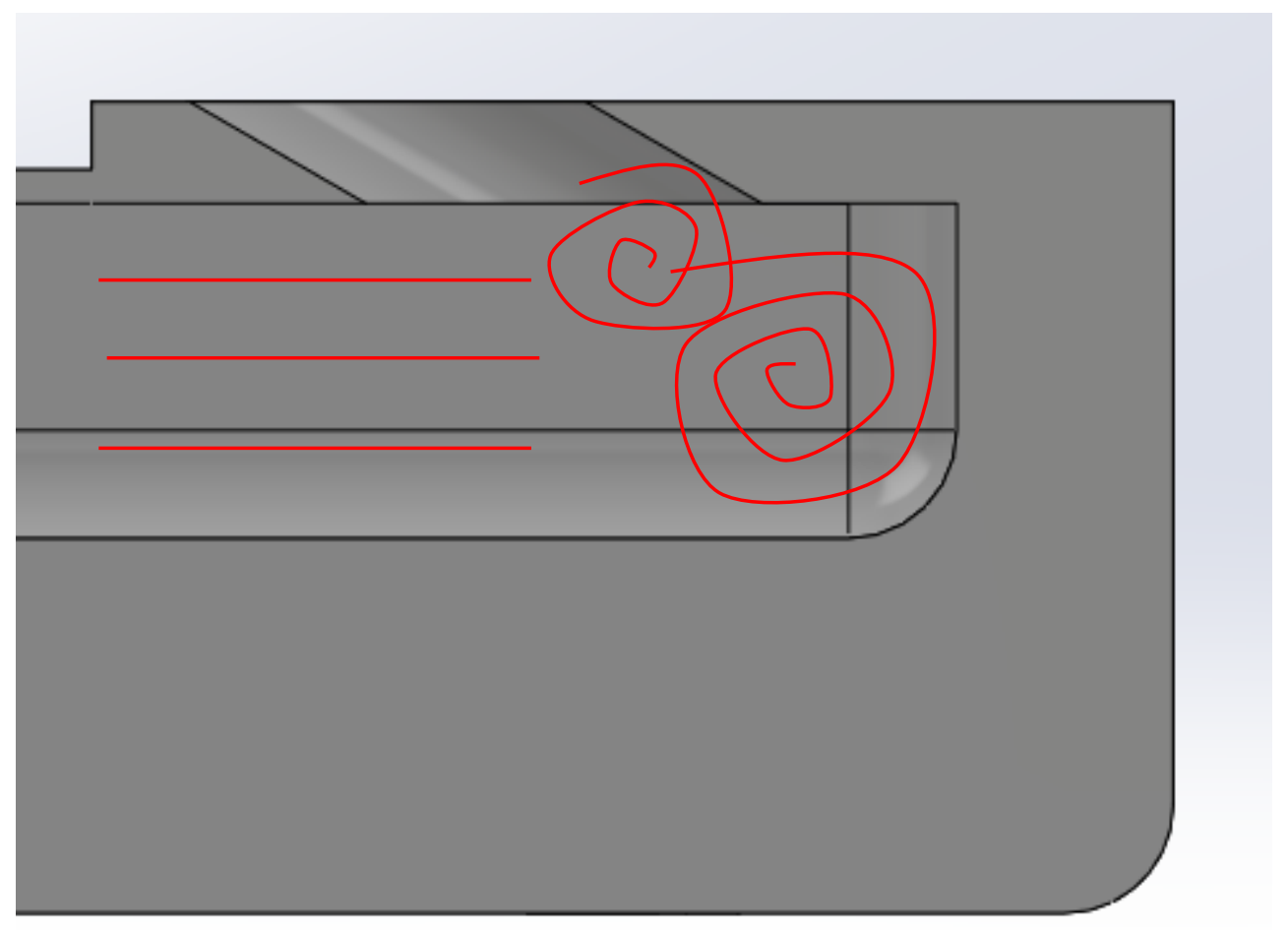

Figure 24: Stagnant air potentially blocking film cooling holes, leading to increase in exit velocity and BR 